\title{
HYDROGEOLOGICAL CHARACTERIZATION AND REGIONAL GROUNDWATER CIRCULATION USING GIS AND MODFLOW MODELS: A CASE STUDY FROM KURUKTAG REGION, NORTHWEST CHINA
}

\author{
ZHENG, J. M. ${ }^{*}$ - XIE, F. \\ Northwest Institute of Nuclear Technology, Xi'an, 710024, China \\ *Corresponding author \\ e-mail:13899012052@163.com \\ (Received 24 $4^{\text {th }}$ Jun 2019; accepted $25^{\text {th }}$ Oct 2019)
}

\begin{abstract}
In order to realize the evaluation of hazardous chemicals disposal sites in the Kuluktag region of Xinjiang, China, this paper conducted a numerical simulation study of the circulation of groundwater in the carrier of nuclide migration. Based on the hydrogeological survey in the field, a hydrogeological conceptual model of regional groundwater flow and a three-dimensional numerical model of regional groundwater flow were established. The finite difference method was applied to obtain the flow velocity and characteristics of groundwater under various scenarios. By analyzing the sensitivity of the structure of water-containing medium and its parameters, this paper aims to explore the impact of the uncertainty of precipitation, water-containing medium structure and its parameters on the flow velocity and direction of regional groundwater, simulate the change of flow velocity and direction of groundwater in the study area, and predict the groundwater circulation rules in the long run measured in the unit of 10,000 years.

Keywords: Kuruktag, hydrogeological conditions, groundwater circulation model, nuclide migration, numerical simulation
\end{abstract}

\section{Introduction}

As groundwater is the carrier of nuclides migration, the quantitative evaluation of groundwater flow and migration of nuclide in underground complex geological bodies is critical to the evaluation and selection of disposal sites. Research and discovery on hydrogeology, groundwater circulation and nuclides migration evaluation is one of the hottest research topics on disposal site evaluation (Kolbe et al., 2016; Post et al., 2019; Cao et al., 2016; Tatti et al., 2019; Zhou et al., 2013; Jiang et al., 2018).

In recent decades, numerical simulation has been carried out extensively to analyze groundwater flow in various areas. Kihm et al. (2007) predicted the relationship between groundwater flow and land deformation using three-dimensional numerical simulation. Blessent et al. (2011) conducted fluid flow and solute transport model in discretely-fractured crystalline bedrock for nuclear-fuel site. Tatti et al. (2019) built numerical model of the contaminated low permeability layers based on groundwater Circulation Wells. Pétré et al. (2019) analyzed the regional groundwater flow system of the transboundary Milk River Aquifer using numerical modeling. Mengistu et al. (2019) employed the numerical simulation to evaluate groundwater monitoring network of the Moab Khutsong deep gold mine.

This article makes full use of existing data, including geological, hydrogeological, groundwater dynamic data and satellite imagery, combined with field hydrogeological surveys to analyze regional hydrogeological conditions and groundwater distribution characteristics, including aquifer media system structure, boundary conditions, characteristics of groundwater flow field, hydraulic connection between different water-bearing units, and characteristics of groundwater recharge and discharge (Chang et al., 2001). 
According to the survey of stratigraphic lithology in combination with the analysis of groundwater dynamic field, geological structure and hydrogeology in the Kuruktag region of Xinjiang, the model of regional groundwater circulation is established, and the numerical model of three-dimensional groundwater flow is constructed to obtain the parameters related to the aquifer system. Based on the existing research results and risk assessment experience at home and abroad (Kendall, 1998; Singleton et al., 2005), the groundwater flow numerical model is used to simulate the spatial and temporal distribution characteristics of groundwater flow under various scenarios, and the influence of the uncertainty of geological medium structure and parameters on groundwater flow is studied and explored. The variation rules of regional groundwater flow under long-term scale could be predicted through the mechanism and pattern of groundwater flow.

(1) We use GIS (Geographic Information System) technology to integrate a large number of regional scale data (including geology, topography, spring location, and well information) into hydrogeological information data. The method not only accurately describes the hydrogeological conditions of the study area, improving the data management and efficiency, but also provides necessary data to support the establishment of regional groundwater models.

(2) Due to the large-scale work area and the difficulties determining hydrogeological boundaries, SRTM DEM (the digital elevation model) data is used for hydrological space analysis, that is, the extraction of digital river network and the division of the drainage basin, so as to grasp the boundary of the whole basin. On the basis of hydrological analysis, the model boundary is determined according to the hydrogeological conditions, flow conditions and replenishment relationship of the work area.

(3) According to the stratigraphic age and lithology, the regional groundwater permeability coefficient is divided. At the same time, considering the strong heterogeneity of the work area, the faults are separately characterized in the model to analyze the impact of faults on groundwater flow.

(4) We aimed to establish a regional groundwater flow model by MODFLOW (Visual MODFLOW 2000 software), and correct the model through the measured groundwater water level so that the regional groundwater model can reflect the real groundwater flow field more accurately.

\section{Hydrogeology introduction}

\section{Natural geographical conditions}

\section{Topography}

The western part of the work area is Bosten Lake by an altitude of about 1,050 m, and the eastern part gradually becomes mountainous. On the north side of the east is the Qoltag Mountains, and on the south side is the Kuruktag Mountain interspersed with the mountain basins. The eastern part of the work area is mainly the Nanhu Gobi. The north side of the work area is the Turpan Basin, and the south faces the Lop Nurdriedbasin. Lop Nur, the lowest plutonium in the Tarim Basin, is a modern dried-up salt lake with an area of $10,350 \mathrm{~km}^{2}$. Its outer zone is the vast Taklimakan Desert in the west; the eastern part is the Beishan and the Aqike Valley; the alluvial fan and dune of the Altun Mountains is in the south, and the low hills of Kuruktag in the north. There are large areas of Yadan or wind-eroded mounds and terraces in the north, west and east of Lop Nur. Lop Nur is an endless salt-desert plain with a slope of only $0.04 \%$. The surface presents different forms of salt crust, which often exhibits micro-topography such as ploughing land and cracks. 
The salt crust is hard and sharp, and the height of the undulation varies from 10 to $60 \mathrm{~cm}$ approximately (Xia, 2007). The surface elevation of the work area is shown in Figure 1.

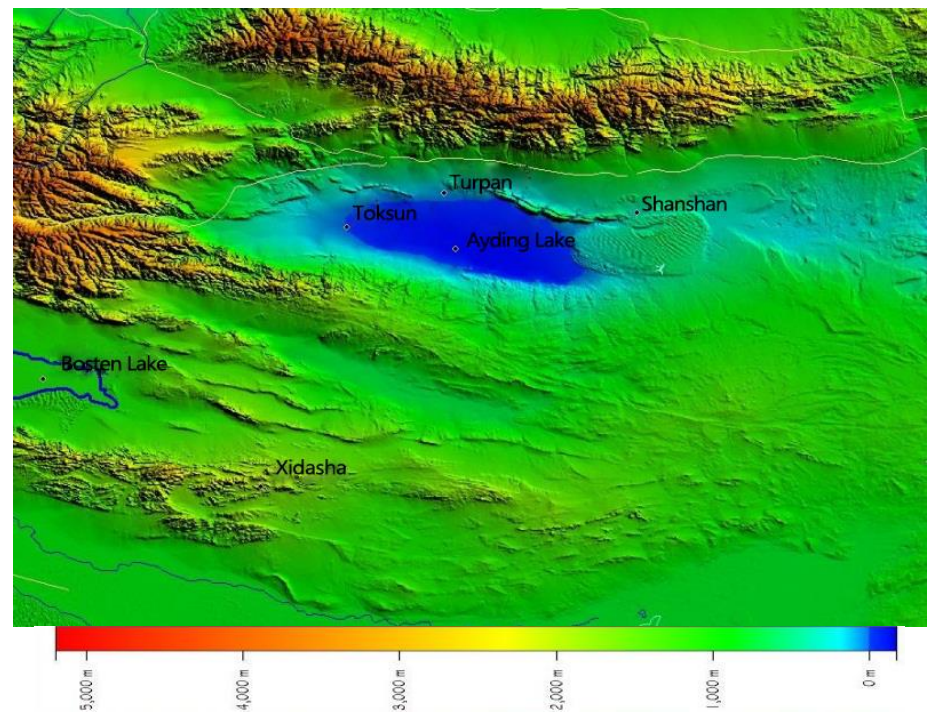

Figure 1. Work area elevation

\section{Meteorology and hydrology}

The work area belongs to the arid area of the northwest inland. The average annual precipitation is less than $60 \mathrm{~mm}$, and the most rainfall is concentrated in the summer. The average annual precipitation of Kumish and Tokson in the west of the work area is $61.6 \mathrm{~mm}$ and $9.2 \mathrm{~mm} ; 26.3 \mathrm{~mm}$ of Shanshan and $56.9 \mathrm{~mm}$ of Hami in the north; $47.8 \mathrm{~mm}$ of Ruoqiang and $42.9 \mathrm{~mm}$ of Milan in the south.

Lop Nur in the south-central part of the work area is located at the lowest recess in the eastern end of the Tarim Basin and surrounded by mountains to the north, east and south of the typical continental arid climate, which means that the region considered to be dry. For example, the average annual precipitation of Tieqianlike is less than $20 \mathrm{~mm}$, however the annual average evaporation is up to $2,600 \mathrm{~mm}$ with $10.6^{\circ} \mathrm{C}$ as the annual average temperature and $26.7^{\circ} \mathrm{C}$ of the average temperature in July, $-9.5{ }^{\circ} \mathrm{C}$ in January. There is a lot of wind in the area, and the prevailing wind direction is NE (SDIC Xinjiang Lop Nur Potash Co. Ltd, 2006).

\section{Geological introduction}

The northern part of the work area is the Turpan-Hami Basin. The Turpan-Hami Basin is an intermountain basin in the eastern section of the Tianshan fold mountain range. It is a Mesozoic and Cenozoic sedimentary basin that occurred and developed on the basis of the returning slanting slope of the Hercynian period. The layer thickness is $5,000-6,000 \mathrm{~m}$ with the maximum of $8,700 \mathrm{~m}$. The southern part of the basin is about $2000 \mathrm{~m}$ above sea level. They are composed of Upper Paleozoic volcanic rocks, volcanic clastic rocks and rammed rocks. The pier uplift divides the Turpan-Hami basin into east and west Quaternary sedimentary basins, and the western part is the Turpan Basin, with an area of about $21,000 \mathrm{~km}^{2}$. The structural pattern of the Tu-ha Basin is shown in Figure 2 (Chen, 1993). 
The central and western part of the work area is the Kuruktag region, and the structure of the area is shown in Figure 3. Most of the Sinian and Paleozoic caprocks were constructed with carbonate platforms and clastic rocks. The total thickness is up to $8,000 \mathrm{~m}$, and the maximum thickness reaches $14,000-15,000 \mathrm{~m}$. When the Tertiary continental clastic sediments are developed, the thickness of the caprock is greatly reduced to only $100-200 \mathrm{~m}$. Due to the different neotectonic movements, the geomorphology of the area is in a relatively young development stage, especially in the northwest, where many high and steep mountains are formed. There is a clear topographical difference between the area and the north of the CazelTaga (geosyncline) and the Tarim Basin (Lot) in the south (Chen, 1966; Feng et al., 1994).

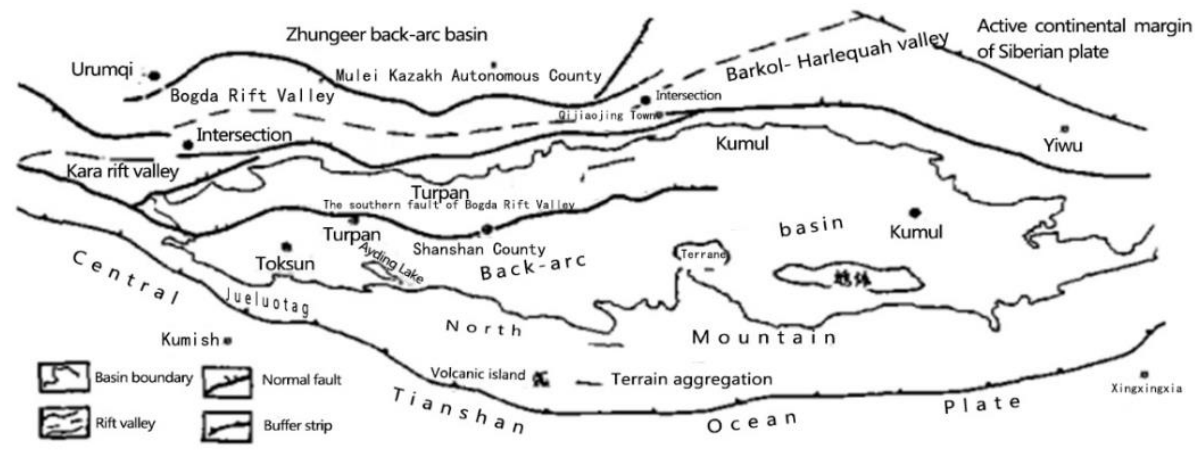

Figure 2. Tectonic framework of the Tu-ha basin and its adjacent area

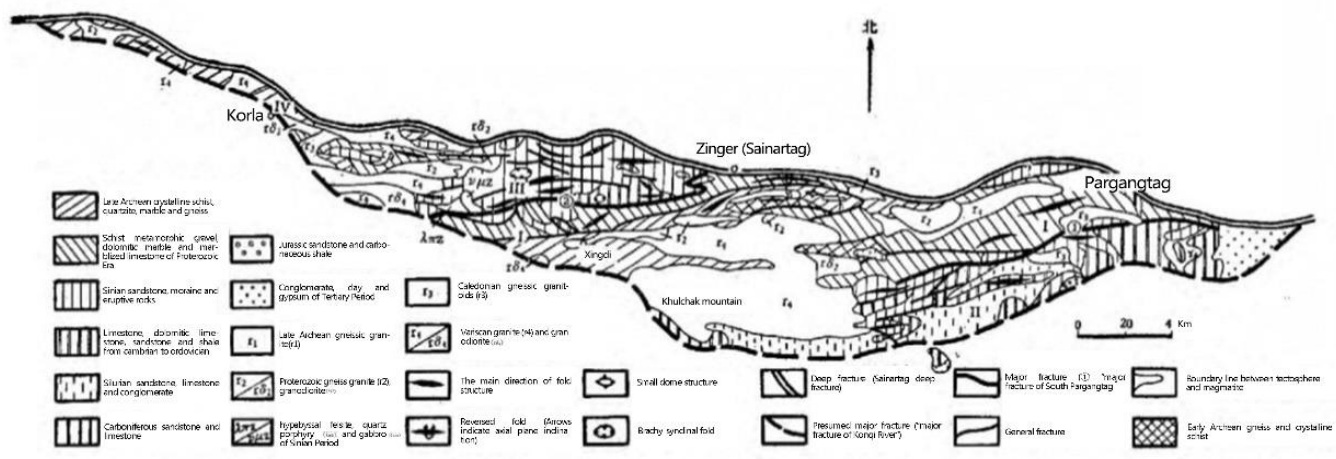

Figure 3. Tectonic sketch of the Kuruktag

\section{Stratum}

The Paleozoic and pre-Paleozoic clastic rocks, magmatic rocks and carbonate rocks are widely distributed in the Kuruktag Mountains. There are thin Quaternary loose stratums distributed in the piedmont strips and local inter-mountain basins. The Tertiary clastic rocks are mainly distributed in the denudation platform and the inter-mountain depression in the northeastern part of the Lop Nur Basin. The formation is generally gentle, and the lithology is mainly mudstone, sandy mudstone, sandstone and glutenite. The Quaternary loose sediments are mainly distributed in the lake basin and its surrounding low-lying areas. The thicker Quaternary alluvial sand and gravel stratums are distributed in the sloping plains of the Altun Mountains in the south and the Aqike Valley in the east. 


\section{Tectonics}

(1) Fracture

There are three lithospheric faults within the work area, and two shell faults, and more general faults. According to its distribution direction, it can be roughly divided into three groups: the north-north-east fault, the near east-west fault and the north-easteast fault, among which the north-east-east fault is the most developed. The near eastwest basal-type fault developed in the Altun Mountains is mostly spread in a sleek shape in a large scale. The main compresso-shearing structure with water-resistance controls the boundary between the bedrock mountain and the basin. The northwestward fault constitutes a conjugated fault zone, which develops in the Kuruktag, Beishan and Aqike Valleys (The Second Hydrogeology Engineering Geology Brigade of Xinjiang Geology and Minerals Bureau, 2003). It extends far with a large scale, and it is regarded as left-handed compresso-shearing, which controls the northern boundary of the driedup Lop Nur salt lake. Across the dried-up Lop Nur salt lake, the fault divide it into several units, and along the fault the spring points are distributed (Shi et al., 2017).

\section{(2) Fold}

There is a large number of folds in diverse forms mainly developed in the Kuruktag and Beishan areas. Among them, the large-scale Beishan fold belt with complex folds is generally north-east-east and north-eastward directed. The fold belt in Kuruktag region is small and omnidirectional in axial direction. In the red clay castle in Luobei, there is a new generation of anticline development.

\section{(3) Joint fissures}

In the Kuruktag and Beishan areas, there are common joint fissures in the rock, and the dense belts are mostly distributed on both sides of the fault. The development of joint fissures in brittle rocks such as limestone and granite are significantly higher than those of soft rocks.

\section{Regional hydrogeological conditions}

\section{Division of groundwater systems}

Based on the viewpoint of groundwater system theory, the complete groundwater migration space with relatively independent recharge, runoff and excretion is divided into six groundwater first-level systems in the region, and then according to aquifer characteristics, recharge conditions, hydrodynamic characteristics and groundwater quality, characteristics, several secondary systems (sub-zones) can be divided (Lei et al., 2019).

\section{Regional groundwater circulation characteristics}

Atmospheric precipitation in the mountainous area is transformed into bedrock fissure water and surface water in the Altun Mountains and Kuruktag and Beishan. Part of the bedrock fissure water is transferred to deep circulation water to the deep subsurface, and the other part along the valley or the front of the mountain to replenish surface water as spring. The surface water flows out of the mountain, passing and then enters the Altun Mountains and Kuruktag and the sloped gravel plains of the Beishan 
Mountain and the front edge of the mountain depressions are turned into springs along the faults and then converted into surface water. It is supplied in the form of lateral replenishment to the Acoch Valley, the Peacock River Delta and the Tarim River Delta alluvial plain, and then to the Lop Nur Lake Plain (Shao et al., 2017). In this migration process, it is excreted by water surface evaporation, phreatic evaporation, plant transpiration and artificial mining. In the vertical direction, the groundwater system is relatively stable and moves upwards and downwards. The water alternates in a mixed type, and the middle and deep layer confined water heads are relatively more. High, the shallow confined water is replenished through faults or relative water-repellent layers, and the shallow confined water is replenished for diving. During this process, the groundwater forms a dynamic equilibrium and the property of water changes from $\mathrm{HCO}_{3}-\mathrm{Ca} \cdot \mathrm{Mg}$ to $\mathrm{SO}_{4} \cdot \cdot \mathrm{Cl}-\mathrm{Ca} \cdot \mathrm{Na}$, which eventually becomes $\mathrm{Cl}-\mathrm{Na}$; in the vertical direction, it also changes from $\mathrm{SO}_{4}-\mathrm{Ca} \bullet \mathrm{Mg}$ to $\mathrm{SO}_{4} \bullet \mathrm{Cl}-\mathrm{Ca} \bullet \mathrm{Na}$, eventually it becomes Cl$\mathrm{Na}$, and then after long-term evaporation and concentration, a highly mineralized potassium-rich brine is formed (Jiao et al., 2004; Liu et al., 1999; Lei et al., 2019; Wang, 2016).

\section{Simulation analysis of regional groundwater flow patterns}

Due to the development of today's groundwater modelling technology and the rapid improvement of computer technology, groundwater numerical model has become an important tool for quantitative study of groundwater movement rules, and plays an increasingly important role in solving specific hydrogeological problems. So far, only through the model, can data from different methods (such as geophysical exploration, drilling, surveying, monitoring, remote sensing, etc.) be put into a unified system for data integration and management, and whether there is any existing contradiction between them. If there is some prior understanding of hydrogeology, it can be analyzed by means of modelling whether the data is consistent with our understanding, which is extremely essential. In the process of comprehensive processing of hydrogeological data by modelling, the sufficient and absent hydrogeological information can be found respectively, which leads to the further exploration of the lacking information. Therefore, the model is also an important means to help deploy further field surveys, and place limited investment on the situations in need of data. We have many assumptions about the flow, excretion, and recharge of groundwater. An effective way to test whether these assumptions are correct is to put the hypothesis into the model and compare the results of the model with the reliable measured results. In this way, we can understand more about hydrogeological conditions.

Groundwater flow is a complex geological process, which means that we cannot directly observe where the groundwater flows to, how fast the water flows, and the spatial variation of aquifer hydrogeological parameters. To comprehend the spatial distribution of groundwater in the ground, the characteristics of groundwater flow and its dynamics over time, scientists have conducted a large number of field surveys and studies in order to master the distribution characteristics and rules of groundwater flow in time and space. Nevertheless, this scientific problem still cannot reach a satisfactory solution for a long time. One of the main reasons is the heterogeneity of the aquifer structure and the uncertainty of its parameters. Because people can only analyze and study aquifer systems based on limited geological and hydrogeological 
exploration data. The hydrogeological community has been seeking for a theory and method that can more reasonably describe the distribution of aquifer system parameters. Therefore, the use of numerical model of three-dimensional groundwater flow to describe the spatial variation characteristics of aquifer structure and groundwater flow rules is the current research trend in the field of hydrogeology.

This paper focuses on the simulation analysis of the groundwater flow pattern in the work area, so as to take in the mode and flow characteristics of regional groundwater circulation.

\section{Mathematical models and numerical methods}

The numerical method has the rules of groundwater flow that can be characterized by complex hydrogeological conditions, artificial activity conditions, irregular boundary conditions, and a series of time variables. After the 1970s, with the development and popularization of computers, numerical methods have been successfully used to simulate groundwater movement and groundwater resource evaluation. The previous numerical simulation research and application of groundwater flow has two distinct features: first, most models discuss numerical algorithms and computational formats, and the processing of boundary conditions is too simple and often insufficient. Many models use artificial boundaries. Whether the artificial boundary selection is reasonable or not will affect the flow pattern of groundwater. The artificial boundary is not a problem in the simulation process. The local parameters can be adjusted to make the calculated value and the measured value reach the expected target. When forecasting, the hydraulic head of the original artificial boundary is generally not given and can only be treated as a known boundary. Second, most studies rely on the two-dimensional model, although in recent years, the use of three-dimensional model has increased, but in practice, few threedimensional models are adopted with few vertical stratifications in the model. More models use idealized research fields and units (rectangular domain regular hexahedron), depending on the aquifer as a horizontal layer. The calculation unit is too idealized and the aquifer is horizontally layered, which is far from the actual distance, bringing about difficulties to reasonably characterize the actual spatial structure changes of the aquifer (Xue et al., 2018).

In this paper, the three-dimensional finite difference model is used to simulate groundwater flow, and the spatial and temporal distribution characteristics of regional groundwater flow are analyzed, and the influencing factors are studied and analyzed.

\section{Mathematical model of three-dimensional groundwater flow}

According to the three-dimensional hydrogeological conceptual model of groundwater flow, the unsteady three-dimensional mathematical model of groundwater flow in the regional aquifer system can be described as follows:

$$
\frac{\partial}{\partial x}\left(K x x \frac{\partial H}{\partial x}\right)+\frac{\partial}{\partial y}\left(K y y \frac{\partial H}{\partial y}\right)+\frac{\partial}{\partial z}\left(K z z \frac{\partial H}{\partial z}\right)=\mu s \frac{\partial H}{\partial t}+W \quad(x, y, z) \in D
$$

Initial conditions:

$$
H(x, y, z, 0)=H_{0}(x, y, z)
$$


Boundary conditions:

$$
\begin{aligned}
& \left.H(x, y, z, t)\right|_{\Gamma 1}=H(x, y, z) \\
& \left.H(x, y, z, t)\right|_{\Gamma 2-1}=Z \\
& \left.K z z \frac{\partial H}{\partial z}\right|_{\Gamma 2-1}=\varepsilon^{\prime}-\left.\mu_{d} \frac{\partial H}{\partial t}\right|_{\Gamma 2-1} \\
& \left.K z z \frac{\partial H}{\partial z}\right|_{\Gamma 2-2}=0
\end{aligned}
$$

where: xyz - Cartesian axis; $\mathrm{t}$ - time; $\mathrm{H}$ - known hydraulic heads; KxxKyyKzz - the main permeability coefficient in the direction of the coordinate axis; $\mu s$ - specific storage; $\mu_{d}$ - gravity specific storage; W - the flow rate per unit volume of the well, taking a negative sign when pumping; $\Gamma 1$ - the Dirichlet boundary; $\Gamma 2-1$ - the boundary of the phreatic surface; $\Gamma 2-2$ - zero flow boundary; $\varepsilon^{\prime}$ - recharge amount of precipitation infiltration.

\section{Numerical methods}

The basic idea of the finite difference method is to replace the continuous vadose zone with a set of finite discrete points in the Vadose zone, as well as replacing the derivative approximated by the difference quotient at the discrete point, and condition the differential equation and its solution as an unknown function. The approximation of the discrete points is an algebraic equation of unknown quantity, and then the difference equation is solved, and then the approximation of the solution of the differential equation at discrete points is obtained.

The method is based on a continuity equation for groundwater flow according to which, the differences between the water flows into and out of a computing element is equal to the change in the water storage capacity of the unit.

The groundwater continuity equation can be expressed as:

$$
\sum Q_{i}=S S \cdot \Delta h \cdot \Delta v
$$

where: $Q_{i}$ - the amount of water flowing into or out of the calculation unit per unit time; SS - the storativity of the aquifer; $\Delta h$ - changes of the hydraulic head per unit time; $\Delta v$ - the volume of the computing element.

After the Vadose zone is split and separated, the computing element can be determined according to the continuity equation and the Darcy formula:

$$
\begin{aligned}
& \sum Q_{i}=S S \cdot \Delta h \cdot \Delta v \\
& Q=K \cdot \omega \cdot \frac{h}{L}
\end{aligned}
$$


The flow into the unit $(\mathrm{i}, \mathrm{j}, \mathrm{k})$ by the computing element $(\mathrm{i}, \mathrm{j}-1, \mathrm{k})$ in the row direction can be obtained as:

$$
q_{i, j-1 / 2, k}=K R_{i, j-1 / 2, k} \Delta c_{i} \Delta v_{k} \frac{\left(h_{i, j-1, k}-h_{i, j, k}\right)}{\Delta r_{j-1 / 2}}
$$

where: $q_{i, j-1 / 2, k}$ - the flow through the interface between the grid points (i, j, k) and (i, j$1, \mathrm{k})\left(\mathrm{L}^{3} \mathrm{~T}^{-1}\right) ; K R_{i, j-1 / 2, k}$ - the permeability coefficient $\left(\mathrm{LT}^{-1}\right)$ between the grid point $(\mathrm{i}, \mathrm{j}$, k) and (i, j-1, k); $\Delta c_{i} \Delta v_{k}$ - cross-sectional area $\left(\mathrm{L}^{2}\right) ; \boldsymbol{h}_{i, j-1 / 2, k}$ the value of the hydraulic head at the grid point $(\mathrm{i}, \mathrm{j}-1, \mathrm{k}) ; \boldsymbol{h}_{\boldsymbol{i}, j, k}$ - the value of the hydraulic head at the grid point (i, j, k); $\Delta r_{j-1 / 2}$ - the distance (L) between the grid point (i, j, k) and (i, j-1, k).

Groundwater flow through the other five interfaces can be analogized. For example, the groundwater flow rate from the grid point $(i, j+1, k)$ to $(i, j, k)$ in the row direction is:

$$
q_{i, j+1 / 2, k}=K R_{i, j+1 / 2, k} \Delta c_{i} \Delta v_{k} \frac{\left(h_{i, j+1, k}-h_{i, j, k}\right)}{\Delta r_{j+1 / 2}}
$$

Similarly, it can be concluded in turn:

$$
\begin{aligned}
& q_{i+1 / 2, j, k}=K C_{i+1 / 2, j, k} \Delta r_{j} \Delta v_{k} \frac{\left(h_{i+1, j, k}-h_{i, j, k}\right)}{\Delta c_{i+1 / 2}} \\
& q_{i-1 / 2, j, k}=K C_{i-1 / 2, j, k} \Delta r_{j} \Delta v_{k} \frac{\left(h_{i-1, j, k}-h_{i, j, k}\right)}{\Delta c_{i-1 / 2}} \\
& q_{i, j, k+1 / 2}=K V_{i, j, k+1 / 2} \Delta r_{j} \Delta c_{i} \frac{\left(h_{i, j, k+1}-h_{i, j, k}\right)}{\Delta v_{k+1 / 2}} \\
& q_{i, j, k-1 / 2}=K V_{i, j, k-1 / 2} \Delta r_{j} \Delta c_{i} \frac{\left(h_{i, j, k-1}-h_{i, j, k}\right)}{\Delta v_{k-1 / 2}}
\end{aligned}
$$

The above formula shows the groundwater flow through the six interfaces of the computing element $(\mathrm{i}, \mathrm{j}, \mathrm{k})$, and the grid spacing and the permeability coefficient are combined into one variable as the hydraulic conductivity coefficient:

$$
C R_{i, j-1 / 2, k}=K R_{i, j-1 / 2, k} \Delta c_{i} \Delta v_{k} / \Delta r_{j-1 / 2}
$$

Applying the hydraulic conductivity to Equations 6 to 11, it can be concluded that:

$$
q_{i, j-1 / 2, k}=C R_{i, j-1 / 2, k}\left(h_{i, j-1, k}-h_{i, j, k}\right)
$$




$$
\begin{aligned}
& q_{i, j+1 / 2, k}=C R_{i, j+1 / 2, k}\left(h_{i, j+1, k}-h_{i, j, k}\right) \\
& q_{i-1 / 2, j, k}=C C_{i-1 / 2, j, k}\left(h_{i-1, j, k}-h_{i, j, k}\right) \\
& q_{i+1 / 2, j, k}=C C_{i+1 / 2, j, k}\left(h_{i+1, j, k}-h_{i, j, k}\right) \\
& q_{i, j, k-1 / 2}=C V_{i, j, k-1 / 2}\left(h_{i, j, k-1}-h_{i, j, k}\right) \\
& q_{i, j, k+1 / 2}=C V_{i, j, k+1 / 2}\left(h_{i, j, k+1}-h_{i, j, k}\right)
\end{aligned}
$$

These formulas are used to calculate the groundwater flow inflows from the six boundary faces of the unit $(i, j, k)$. In addition, the effects of other various external sources and sinks on the calculation unit, such as rivers, ditches, production wells, and injection wells, evapotranspiration, etc. need to be considered. The quantity of these sources and sinks into the unit can be calculated by a formula:

$$
\boldsymbol{a}_{i, j, k, n}=\boldsymbol{p}_{i, j, k, n} \boldsymbol{h}_{i, j, k}+\boldsymbol{q}_{i, j, k, n}
$$

where: $a_{i, j, k, n}$ - the replenishment of the nth external source pair calculation unit (i, j, k) (L3 T-1); $q_{i, j, k, n}, p_{i, j, k, n}$ - constant, the unit is (L2 T-1), (L3 T-1).

Considering the six adjacent grid points of the calculation unit and all the sources and sinks contained in the unit, the continuity equation $(E q .4)$ can be calculated as:

$$
\begin{aligned}
& q_{i, j-1 / 2, k}+q_{i, j+1 / 2, k}+q_{i-1 / 2, j, k}+q_{i+1 / 2, j, k}+q_{i, j, k-1 / 2}+q_{i, j, k+1 / 2}+\sum_{n=1}^{N} a_{i, j, k, n} \\
& =S S_{i, j, k} \frac{\Delta h_{i, j, k}}{\Delta t} \Delta r_{i} \Delta c_{j} \Delta v_{k}
\end{aligned}
$$

where: $S S_{i, j, k}$ - the storativity of the computing element $\left(\mathrm{L}^{-1}\right) ; \frac{\Delta h_{i, j, k}}{\Delta t}$ - a differential approximation of the partial derivative of the hydraulic head for time; $\Delta r_{i} \Delta c_{j} \Delta v_{k}-$ the volume of computing element $\left(\mathrm{L}^{3}\right)$.

Substituting Equations 13-18 and 19 into Equation 20 yields:

$$
\begin{aligned}
& C R_{i, j-1 / 2, k}\left(h_{i, j-1, k}-h_{i, j, k}\right)+C R_{i, j+1 / 2, k}\left(h_{i, j+1, k}-h_{i, j, k}\right)+C C_{i-1 / 2, j, k}\left(h_{i-1, j, k}-h_{i, j, k}\right)+ \\
& C C_{i+1 / 2, j, k}\left(h_{i+1, j, k}-h_{i, j, k}\right)+C V_{i, j, k-1 / 2}\left(h_{i, j, k-1}-h_{i, j, k}\right)+C V_{i, j, k+1 / 2}\left(h_{i, j, k+1}-h_{i, j, k}\right)+ \\
& P_{i, j, k, n} h_{i, j, k}+Q_{i, j, k, n}=S S_{i, j, k} \frac{\Delta h_{i, j, k}}{\Delta t} \Delta r_{i} \Delta c_{j} \Delta v_{k}
\end{aligned}
$$

The partial derivative of the hydraulic head to time is approximated by the difference quotient: 


$$
\frac{\Delta h_{i, j, k}}{\Delta t} \approx \frac{h_{i, j, k}^{m}-h_{i, j, k}^{m-1}}{t_{m}-t_{m-1}}
$$

Then all the flows are based on the end time $t_{m}$ of a certain time period, then Equation 21 becomes:

$$
\begin{aligned}
& C R_{i, j-1 / 2, k}\left(h_{i, j-1, k}^{m}-h_{i, j, k}^{m}\right)+C R_{i, j+1 / 2, k}\left(h_{i, j+1, k}^{m}-h_{i, j, k}^{m}\right)+C C_{i-1 / 2, j, k}\left(h_{i-1, j, k}^{m}-h_{i, j, k}^{m}\right)+ \\
& C C_{i+1 / 2, j, k}\left(h_{i+1, j, k}^{m}-h_{i, j, k}^{m}\right)+C V_{i, j, k-1 / 2}\left(h_{i, j, k-1}^{m}-h_{i, j, k}^{m}\right)+C V_{i, j, k+1 / 2}\left(h_{i, j, k+1}^{m}-h_{i, j, k}^{m}\right)+ \\
& P_{i, j, k, n} h_{i, j, k}^{m}+Q_{i, j, k, n}=S S_{i, j, k} \frac{h_{i, j, k}^{m}-h_{i, j, k}^{m-1}}{t_{m}-t_{m-1}} \Delta r_{i} \Delta c_{j} \Delta v_{k}
\end{aligned}
$$

The above equations are iteratively solved. At the beginning, the unknown computing element to each hydraulic head is assigned to the initial head or the estimated head, and the result of each iteration is used for the next calculation.

According to the difference equation, the matrix form of the system of equations can be concluded:

$$
[\mathrm{A}]\{\mathrm{h}\}=[\mathrm{q}]
$$

where: [A] - the coefficient matrix of the hydraulic head; - the requested matrix of the hydraulic head; [q] - All absolute terms and known terms contained in each equation.

In MODFLOW, the coefficient matrix and the right term are gradually established by each software package. Finally, MODFLOW solves by iteration based on these two matrices.

\section{Software for realizing numerical simulation of $3 D$ flow}

Visual MODFLOW 2000 software was used to build a finite difference model for groundwater flow and particle migration in this workspace. Visual MODFLOW is the most complete and user-friendly 3D groundwater flow and contaminant transport simulation software for practical applications. This complete integrated software combines MODFLOW, MODPATH and MT3D with an intuitive and powerful graphical user interface to easily determine the size of the simulation area, select parameter units, set model parameters and boundary conditions, and run model simulations (MT3D, MODFLOW, and MODPATH), correcting the model and visualize the model mesh, inputting parameters and results in the form of sections and plans.

\section{Regional groundwater flow modelling}

\section{Model boundary}

On the account of the large-scale work area and the difficulties of hydrogeological boundary to be determined, first, the SRTM DEM data is used for hydrological space analysis, digital river network extraction and watershed division, so as to have a brief knowledge of the boundary in terms of the whole basin. The DEM elevation map of the work area is shown in Figure 1. 
SRTM is the abbreviation of The Shuttle Radar Topography Mission, which was completed in February 2000. Most of its data is located between $60^{\circ}$ north latitude and $56^{\circ}$ south latitude, covering $80 \%$ of the continent. SRTM includes two resolutions: SRTM1, only covering the continental United States with a resolution of $1 \mathrm{~s}$ of arc; SRTM3, with global coverage and a resolution of $3 \mathrm{~s}$ of arc. Due to the areas without data in SRTM DEM database, the CGIAR-CSI SRTM3, the SRTM DEM product processed by CIAT (International Tropical Agriculture Center) can also be used, which has released the latest V3 version recently with two formats named as arc-formatted ASCII and GeoTIFF. The CGIAR-CSI SRTM3 DEM in GeoTIFF format downloaded from CIAT, which is referred to as SRTM3 DEM, is used in this study. The SRTM3 elevation reference is the geoid of the EGM96 and the planar reference is WGS84. SRTM3 has an accuracy of $3 \mathrm{~s}$ arc, which divides the area of 1 square degree into 1,200 $\times 1,200$ small areas, each small area is $3 \mathrm{~s}(90 \mathrm{~m} \times 90 \mathrm{~m})$ in size, and each small area has a value representing the elevation of the center of the area. The SRTM3 DEM data is equivalent to 1:250,000 scale map data. The $3 \mathrm{D}$ perspective of the work area is shown in Figure 4.

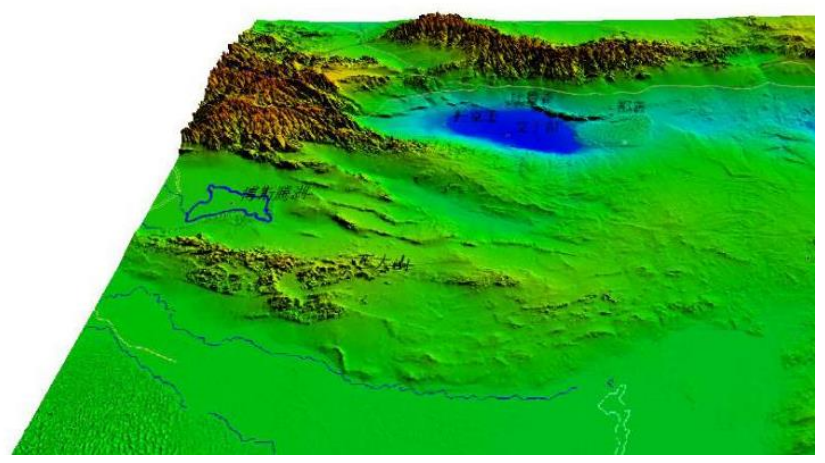

Figure 4. Three-dimensional view of the work area

Hydrological analysis is an important aspect of DEM data applications. The use of DEM to generate catchment basins and water flow networks to analyze surface water flow conditions is an important application as well as the great significance for comprehension of the shape of the Earth's surface. The main content of surface hydrological analysis based on DEM is to use hydrological analysis tools to extract the flow direction, the cumulative amount of flow, the length of water flow, the river network (including the classification of river networks, etc.) of the surface water runoff model, and the division of the watershed in the work area. By extracting these basic hydrological factors and basic hydrological analysis, the process of water flowing can be redisplayed on the surface of the DEM, contributing to the hydrological analysis process eventually.

The hydrological analysis mainly constitutes the direction of surface water flow in the region and the possible surface watersheds in each basin. Therefore, the analysis core is placed on the extraction of river networks and the division of watersheds.

The basic flow of extracting digital river network and watershed based on DEM data is as follows (Wang et al., 2018):

(1) DEM data preprocessing. Before extracting the digital river network of the watershed by using DEM data, the data is supposed to be preprocessed to eliminate the 
invalid data area existing in the DEM. In addition, since the DEM data itself often has a lot of depressions and plane ground, as a result, the DEM data such as the determination of the DEM data and the filling of the depression and the lifting of the ground must be pre-processed, after the valid DEM data is available in order to obtain effective DEM data for river network water extraction.

(2) The grid flow direction is determined. After the pre-processed valid DEM data is in hand, the flow direction of each raster in the data can be determined. The method of judging the flow direction mainly includes a multi-flow method and a single flow method. As specified, the single flow method is so simple and convenient that it can be extensively used, among which D8 is the most widely used one. The D8 method assumes that there are only eight possible flow directions in the water flow in a single grid, that means, the water flow will flow into the eight adjacent grids. It uses the steepest slope method to determine the direction of the water flow, that is to calculate the distance weight difference between the center grid and each adjacent grid (i.e., the grid center point drop divide the distance between the gridcenter points) on the $3 \times 3$ DEM grid, the grid with the largest distance drop is the outflow grid of the center grid, which is the flow direction of the center grid.

(3) Determination of the water flow accumulation matrix. Based on the determined water flow direction data, the upstream water supply area range of each grid unit is accumulated, which means to determine the specific upstream grids flow direction to be cumulatively directed to the grid unit.

(4) Drainage networks extraction. Set the catchment area threshold to the flow accumulating grid according to the threshold value, then the river network grid network map of the area can be obtained to generate a digital drainage network.

(5) Watershed division. The drainage basin collects all kinds of precipitation divided by watersheds. It determines all the grids that are interconnected and in the same basin by analyzing the water flow direction data. The first step of determination of the drainage basin is to determine the location of the outlet at the edge of the analysis window that is to say, in the division of the drainage basin, the outlets of all drainage basins are at the edge of the analysis window. When the location of the water outlet is determined, the determination of the collection area of the drainage basin is similar to that of the contribution area of the depression, equal to the location of all upstream grids flowing into the outlet.

After the GIS hydrological space analysis, the river network and watershed model of the work area can be obtained, as shown in Figure 5.

It is better to build the regional groundwater model with the natural hydrogeological boundaries as far as possible from a holistic perspective. It is assumed that the watershed at the surface drainage basin is also a ground watershed, so the surface watershed of the drainage basin obtained by hydrological space analysis is treated as a groundwater watershed with a zero flux boundary. However, due to the asymmetry of precipitation recharge and topography, the watershed of surface water and surface water is inconsistent, but the impact on groundwater simulation in large areas is acceptable.

Based on the analysis results, the model boundaries are generalized as follows:

- West Bosten Lake is a type of head boundary.

- The eastern part is the lateral replenishment boundary, defined as the Neumann boundary.

- The northern part of Aidin Lake is defined as Dirichlet head boundary.

- Southern Lop Nur is the evaporation boundary. 
- The other boundary is the flux boundary.

- The vertical top boundary of is the phreatic boundary, and the model is divided to the surface, directly accepting the recharge of atmospheric precipitation and evaporation and drainage, leading to a definition as the flux boundary in the form of source and sink items in the model.

- The vertical bottom boundary is the Neumann confining boundary (zero flux boundary).

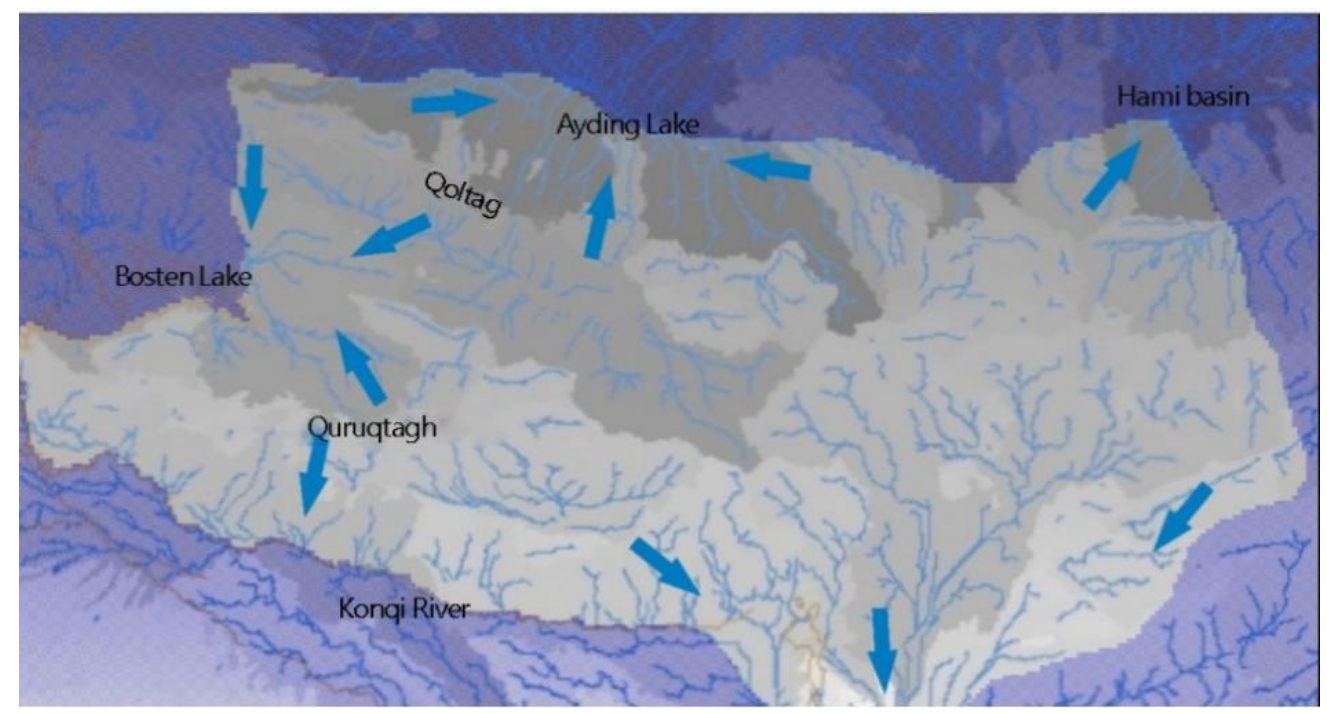

Figure 5. Work area hydrological space analysis results

\section{Model splitting}

The work area is divided by a rectangular hexahedron (the upper and lower planes are not necessarily parallel).

The model is discretely divided into 160 rows and 285 columns, each of which has a length and width of $2 \mathrm{~km}$ (Fig. 6). The vertical model is divided into three layers, each of which has a constant thickness. The thickness of the three layers is $0-1,000 \mathrm{~m}, 1,000$ $1,800 \mathrm{~m}, 1,800-2,600 \mathrm{~m}$ from the top to the bottom, and each layer is not horizontally distributed. The vertical division into three layers is the most simplified way of performing three-dimensional numerical simulation. As the geological survey of the work area is deepened, it will be continuously improved to accurately describe the spatial distribution of the aquifer. The bottom of the model is $2,600 \mathrm{~m}$ below the surface of the submerged surface. It is assumed that the groundwater is mainly horizontally flowing at this depth.

The total model is split into 136,800 units in total, of which 79,356 are effective and 57,444 are invalid ones.

Aiming at solving the problem of insufficient terrain data of large-area model, SRTM DEM data is used to establish groundwater space model, and high-precision surface elevation characterization can effectively improve the calculation accuracy of groundwater model phreatic evaporation. 


\section{Parameter partitioning}

(1) Horizontal permeability coefficient

The horizontal permeability coefficient division is mainly conducted according to the 1:2.5 million scale geological map of the working area, as shown in Figure 7, mainly considering the dominant hydrogeological features, including granite, shale, clasticrocks, Quaternary sediments, etc. It is divided into different coefficient partitions and reflected in the model to obtain a heterogeneous parameter model. The consideration of heterogeneous characteristics is more in line with the actual hydrogeological conditions and can better reflect the groundwater flow conditions in the area.

It could be reduced to three parameter partitions: high permeability performance partition (K1), medium permeability performance partition (K2), and low permeability performance partition (K3). The permeability coefficient parameter partitioning is discontinuous, and each partition contains several units in the model, as shown in Figure 8.

According to the research results of the permeability coefficient of the predecessors in the work area (see Table 1), combined with the characteristics of the regional groundwater model, the basic values of the three partition permeability coefficients are defined in Table 2.

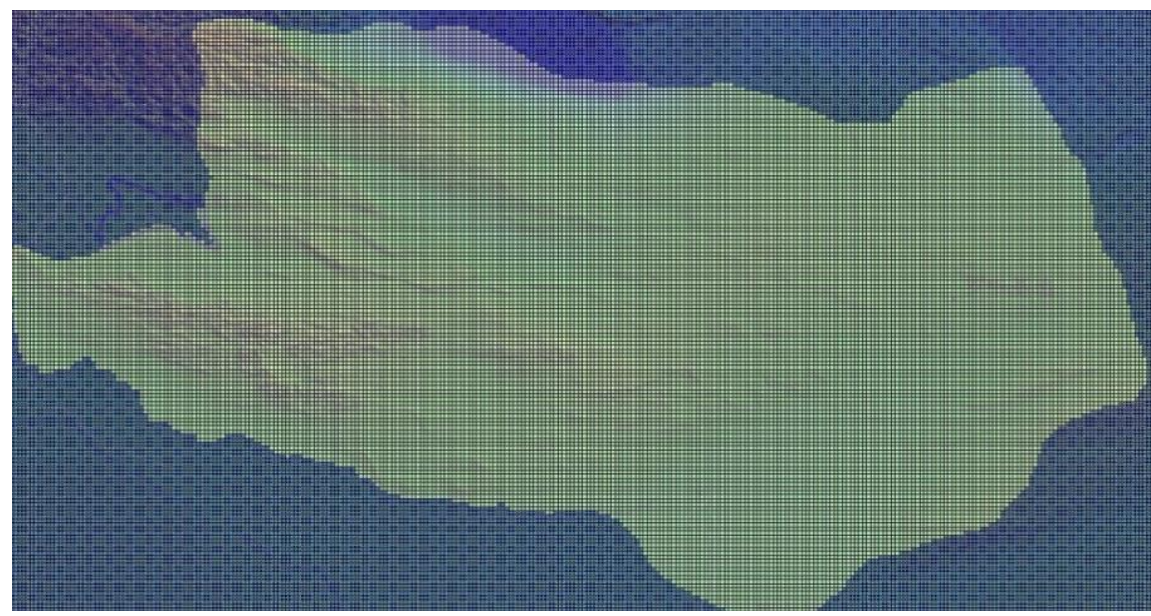

A Plane split diagram

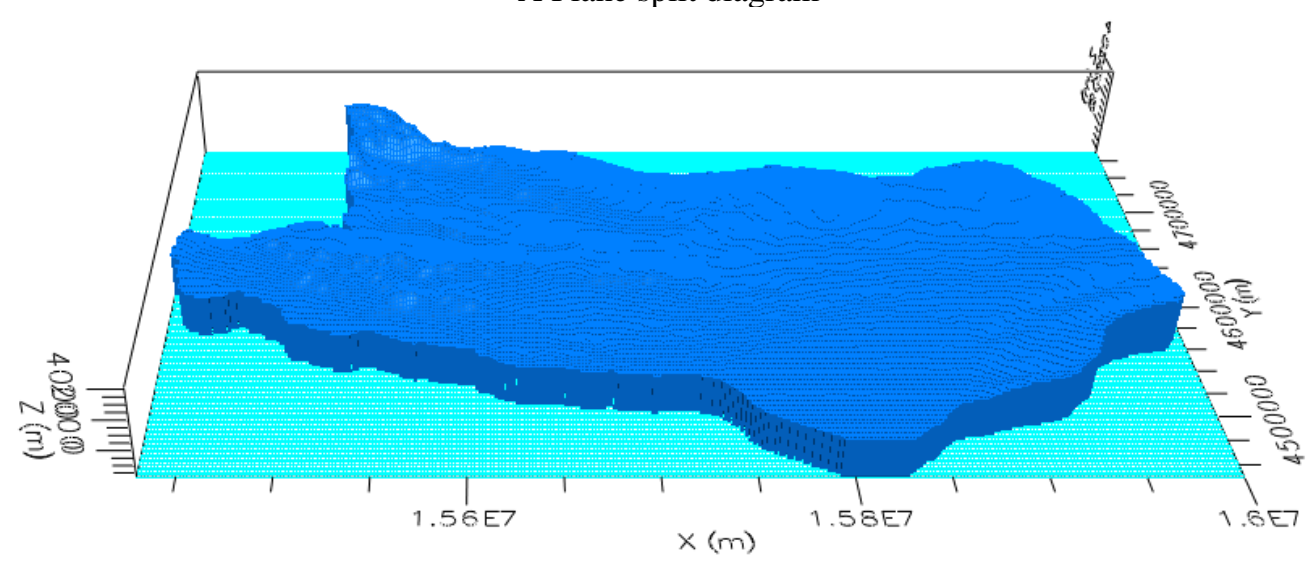

B Stereoscopic view

Figure 6. Model split diagram 


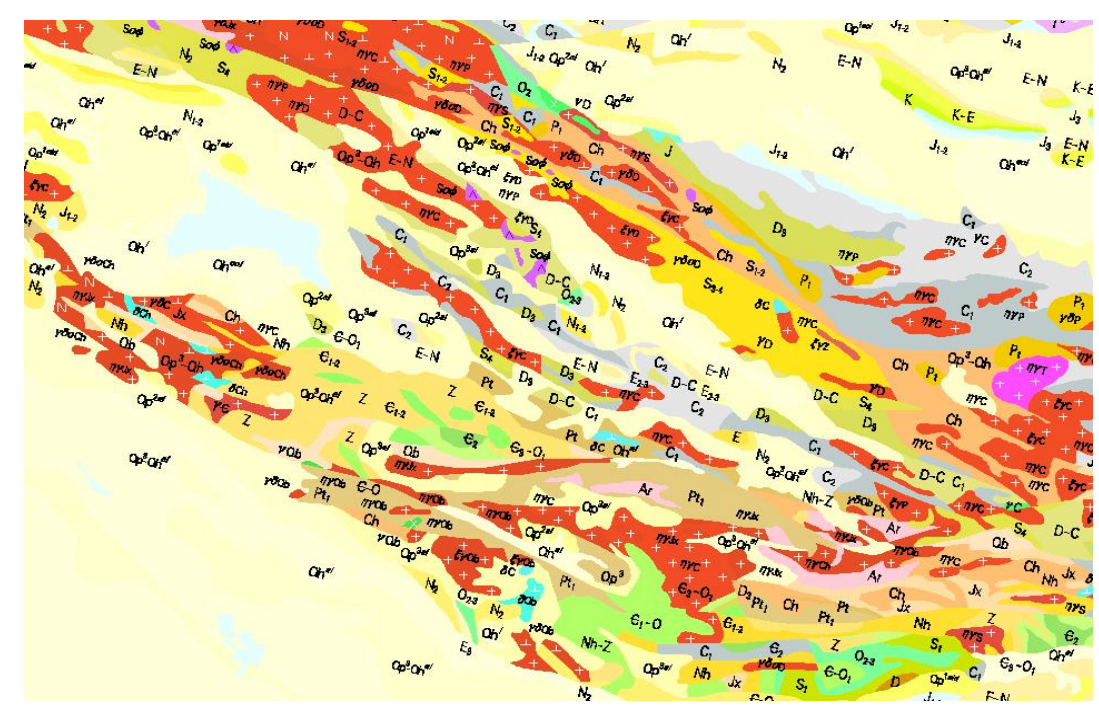

Figure 7. Geological map of work area

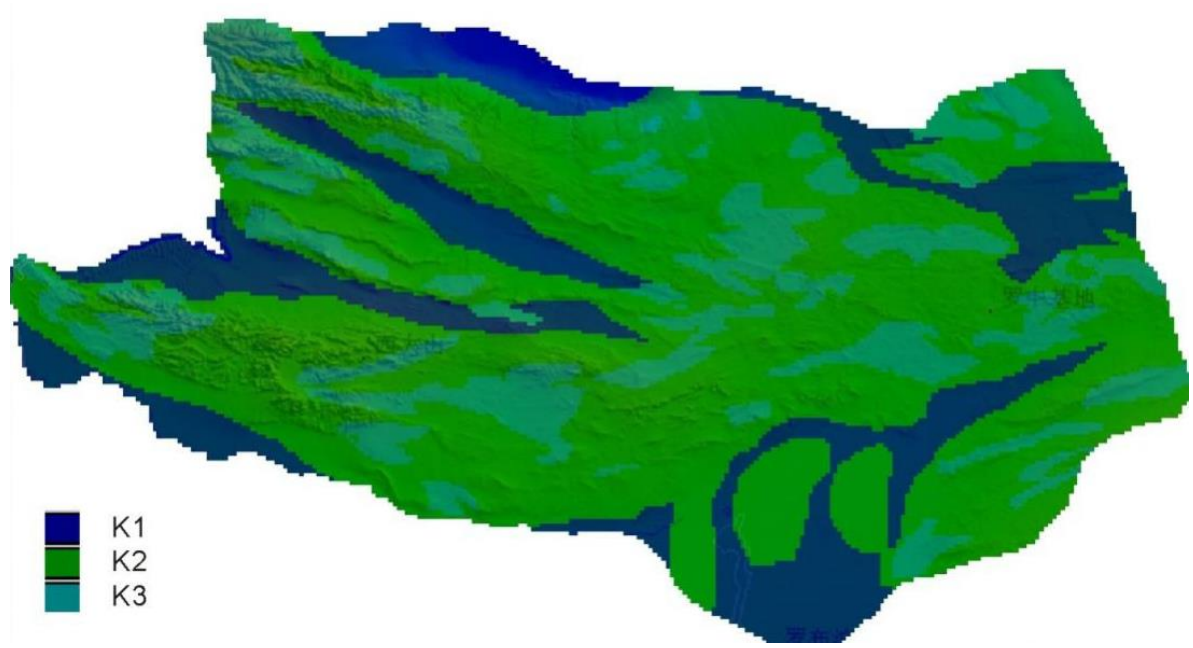

Figure 8. Horizontal permeability coefficient partition map

Table 1. Permeability coefficient of work area

\begin{tabular}{c|c}
\hline Groundwater location and type & Permeability coefficient value (m/d) \\
\hline Peacock river alluvial delta pore water & $0.14-5.73$ \\
Aqike valley unit & $0.621-4.49$ \\
Luobei concave ground pores and intercrystalline pore water & $0.5-80$ \\
Lop Nur dry salt lake pores and intercrystalline pore water & $<1.0$ \\
\hline
\end{tabular}

Table 2. Partition values of each permeability coefficient of the model

\begin{tabular}{c|c}
\hline Partition & Permeability coefficient value (m/d) \\
\hline K1 High permeability performance partition & 2.0 \\
K2 Medium permeability performance division & 0.26 \\
K3 Low permeability performance zone & 0.004 \\
\hline
\end{tabular}


The permeability coefficient values for each partition will be scaled up or down during multiple scenario simulations to analyze the uncertainty of the parameters.

(2) Vertical permeability coefficient

The vertical permeability coefficient partition is consistent with the horizontal permeability coefficient partition. According to the geological conditions and empirical values of the working area, the ratio of the vertical permeability coefficient to the horizontal permeability coefficient in the model is 0.25 , and the trial calculation is carried out in the model.

\section{(3) Precipitation}

The average annual precipitation of the working area is shown in Table 3, and the precipitation parameters can be divided according to different regions.

Table 3. Annual average precipitation statistics of the work area

\begin{tabular}{c|c|c}
\hline Area & Statistical time period & Annual average precipitation (mm) \\
\hline Milan & $2,004-2,005$ & 42.9 \\
Lop Nur Town & 2,005 & 29.3 \\
Kumish & $2,001-2,005$ & 61.6 \\
Toksun & $2,001-2,005$ & 9.2 \\
Yan Shan & $2,001-2,005$ & 29.3 \\
Hami & $2,001-2,005$ & 56.9 \\
Qarkilik & $2,001-2,005$ & 47.8 \\
\hline
\end{tabular}

According to the " 95 " national key scientific and technological research project, the effective precipitation infiltration rate of the Hexi Corridor area (climate condition which is similar to that of the Lop Nur area) is 30-50\%. Depended on the previous research results, the infiltration recharge of atmospheric precipitation in different depths of Luobei depression is shown in Table 4.

Table 4. Recharge of atmospheric precipitation infiltration in different depths of Luobei depression

\begin{tabular}{c|c|c|c}
\hline Groundwater depth $(\mathrm{m})$ & $1.0-1.5 \mathrm{~m}$ & $1.5-2.0 \mathrm{~m}$ & $>2.0 \mathrm{~m}$ \\
\hline Rainfall infiltration coefficient & 0.235 & 0.15 & 0.11 \\
\hline
\end{tabular}

According to different rainfall infiltration coefficient and precipitation, the rainfall infiltration in each region can be obtained.

Calculation formula:

$$
\mathrm{Q} \text { drop }=\mathrm{A} \cdot \beta
$$

where: Q drop - atmospheric precipitation infiltration recharge $\left(10^{4} \mathrm{~m}^{3} / \mathrm{a}\right) ; \mathrm{A}$ - year effective precipitation; B - effective precipitation infiltration coefficient.

The effective precipitation infiltration in each region can be determined by model identification. 
(4) Evaporation

See Table 5 for the phreatic evaporation coefficient of in different regions of the work area. See Table 6 for the phreatic evaporation in different areas.

Table 5. List of different buried depth underground water coefficients in different regions

\begin{tabular}{c|c|c|c|c|c|c|c|c}
\hline \multirow{2}{*}{ Area } & \multicolumn{7}{|c|}{ Buried depth } \\
\cline { 2 - 9 } & $\mathbf{0 . 5} \mathbf{~ m}$ & $\mathbf{1 . 0} \mathbf{~ m}$ & $\mathbf{1 . 5} \mathbf{~ m}$ & $\mathbf{2 . 0} \mathbf{~ m}$ & $\mathbf{2 . 5} \mathbf{~ m}$ & $\mathbf{3 . 0} \mathbf{~ m}$ & $\mathbf{3 . 5} \mathbf{~ m}$ & $\mathbf{4 . 0} \mathbf{~ m}$ \\
\hline Yumen Station & 0.174 & 0.116 & 0.060 & 0.047 & 0.028 & 0.019 & 0.015 & 0.009 \\
Turpan Station & 0.253 & 0.149 & & 0.051 & & & & 0.021 \\
Gunke Station & 0.164 & 0.112 & 0.076 & 0.050 & 0.040 & 0.028 & & 0.014 \\
\hline
\end{tabular}

Table 6. List of underground water evaporation in each region

\begin{tabular}{c|c}
\hline Area & Evaporation $(\mathbf{m m})$ \\
\hline Aqike Valley & 2,500 \\
Yumen Town & $2,511.9$ \\
Turpan & $2,837.8$ \\
Gunke & 2,700 \\
\hline
\end{tabular}

Regarding the formula of the evaporation law of diving, we use the empirical formula (index formula) obtained in the article Study on water transport and equilibrium factors of the aeration zone in the middle reaches of the Heihe River in Gansu Province (internal data from Second Hydrogeological Institute of Gansu Province, 1995):

$$
\varepsilon=\varepsilon_{0} \cdot e^{-b D}
$$

where: $\varepsilon$ - diving evaporation intensity; $\varepsilon_{0}$ - water surface evaporation intensity; $D$ diving depth; $b$ - Experience factor (related to soil quality), determined by model identification.

\section{Numerical simulation and correction of regional groundwater flow}

Due to the large scope of the work area in remote areas in the northwest, the researches on hydrogeological work area are relatively less, so there is a lack of dynamic data required for the simulation of groundwater unsteady flow, such as longterm water level observation data, monthly precipitation, monthly evaporation, etc., so the use of multi-year average data in the study for stable flow simulation, focusing on the characteristics of the water cycle in the work area.

\section{Stable flow simulation}

On the strength of average data of multiple years, the permeability coefficient is taken as a basic combination for steady flow numerical simulation. The simulation results are shown in Figure 9.

There are multiple groundwater flow systems in the area by the regional groundwater flow field. In the vicinity of the Turpan Basin in the northern part of the work area, 
groundwater mainly flows from the Qoltag Mountain and the eastern side of the basin to the Aiding Lake; the southwestern side of the Qoltag Mountain and the northwest side of the Kuruktag are collected from the Bosten Lake; the groundwater in the south of Kuruktag mainly flows along the Peacock River to Lop Nur; the groundwater in the northeastern part of the working area flows from the west and south to the sand lake in the Hami Basin; the eastern part of the working area receives the lateral recharge of the downstream of the Shule River and flows to Lop Nur (Zhu et al., 2001).

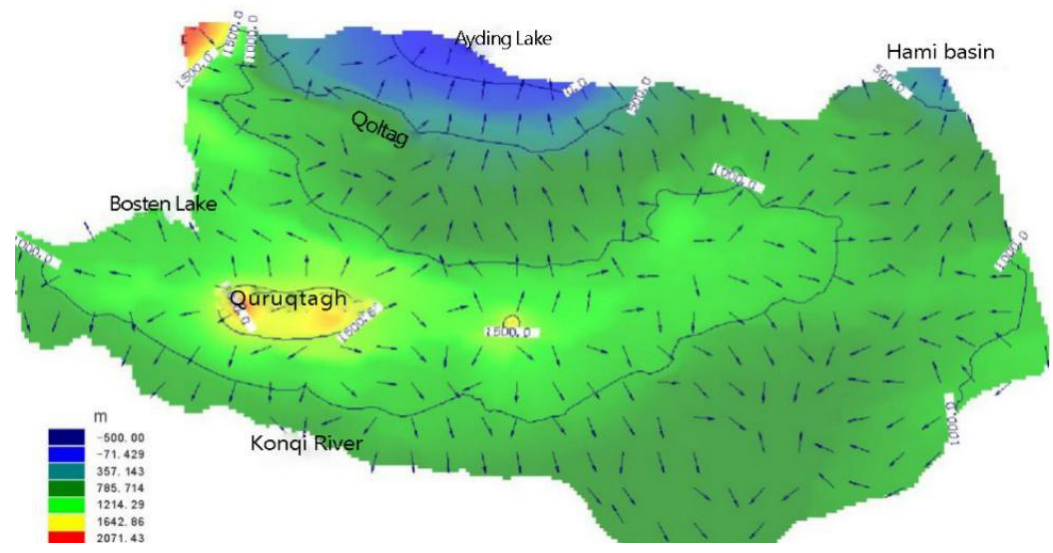

Figure 9. Basic model steady flow field

\section{Model adjustment}

Due to the lack of water level observation data in the working area, the groundwater heads formed by interpolation of some measured groundwater data in the area are compared with the simulated preliminary flow field, and the differences are analyzed. The parameters in the model are then adjusted according to the hydrogeological conditions of different locations. The adjusted and simulated flow field and the measured value interpolated flow field are shown in Figure 10.

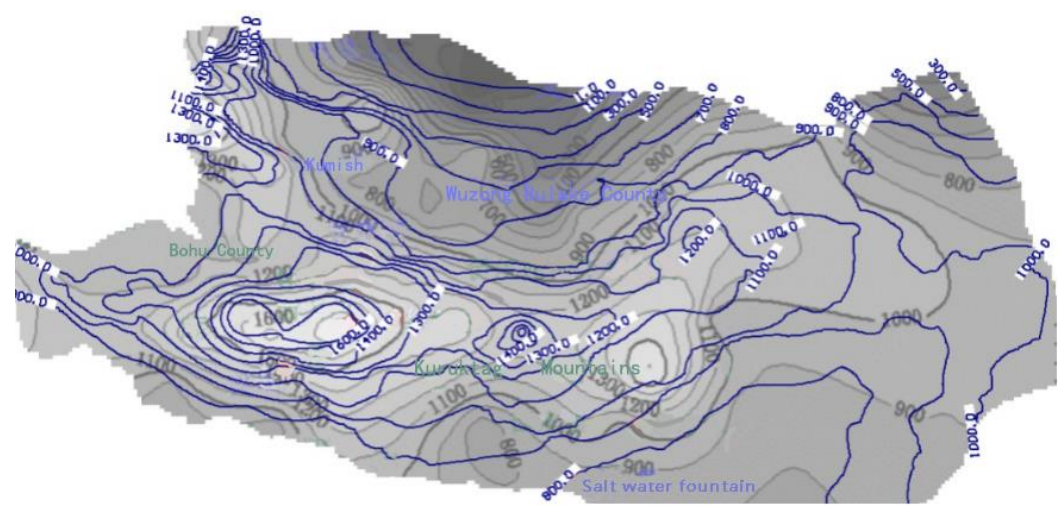

Figure 10. Comparison of measured and simulated groundwater level contours (blue lineanalog value, black-measured value)

It can be seen from Figure 10 that the simulated flow field is consistent with the measured flow field as a whole, but there are certain differences in some parts mainly resulting from the following reasons: 
(1) Insufficient measured groundwater level data causes local distortion of the interpolation flow field, which cannot fully represent the real groundwater flow field. The work area is over $100,000 \mathrm{~km}^{2}$, but there are only a few dozen groundwater data for interpolation, especially in the eastern part of the work area, with fewer interpolation points. Taking the northern part of Dongshuiquan as an example, there is a high water point in the measured interpolation flow field, but in fact it is not the highest point of the surrounding elevation, and there is no other water supply, just because there are no other interpolation points nearby.

(2) On the account of large working area but less relevant geological and hydrogeological information, the model based on the water quantity information cannot completely simulate the local and detailed groundwater flow characteristics in the area. The lack of basic data in the work area, the characterization of geological structures and the treatment of source and sink items such as precipitation and evaporation are not able to reach high standards, giving rise to the lack of ability to characterize small cycles in local areas such as small basins in the mountains.

Although there is a lack of local details and precision, the model initially depicts the unaffected characteristics of groundwater flow with the overall regional perspectives which can support the analysis of regional groundwater circulation.

\section{Multi-scenario particle tracer simulation analysis}

In order to analyze the particle migration in key areas of the work area, the MODPATH software was used to simulate the particle tracing under multiple scenarios with comprehensive consideration of the uncertainty of the parameters.

MODPATH is a convection transmission simulation software that can acquire groundwater model and simulation result data from MODFLOW and calculate the particle migration trajectory. MODPATH uses a semi-analytical solution for particle tracking to calculate groundwater migration routes and flowing time. The method assumes that the velocity components in each direction of each grid cell vary linearly in their own coordinate direction, allowing us to get an analytical expression that describes the streamlines within the grid cell. Given any initial position of the mass point in the cell, the coordinates of other points on the streamline within the cell and the time interval between the groundwater masses passing through the two points can be calculated.

Through the graphical interaction interface of MODPATH, the user can use the mouse to click to set the particle point and demonstrate of the particle migration. Most particle migration simulation software requires post-processing to get the route and time visualization results, however it can be calculated and displayed simultaneously on the MODPATH. MODPATH also provides a variety of data display functions for any selected model layer and time step, such as displaying the water head contour, the drop contour, and the flow rate and direction.

It is assumed that the nuclide is the ideal particle, that is to say, the program module can be used to conveniently simulate the migration trajectory of the nuclide particle under different scenarios without consideration of the reaction of the nuclide-water-rock.

According to the research geological map, three large-area granite areas located in the eastern and central parts of the work area were selected for particle tracing simulation. The position of the tracer particles is shown in Figure 11. In the central region of each granite zone, 20 particles were placed on a circumference with a radius of $5 \mathrm{~km}$. The particles in the simulation are shown in green and the migration trajectory is shown in red. 


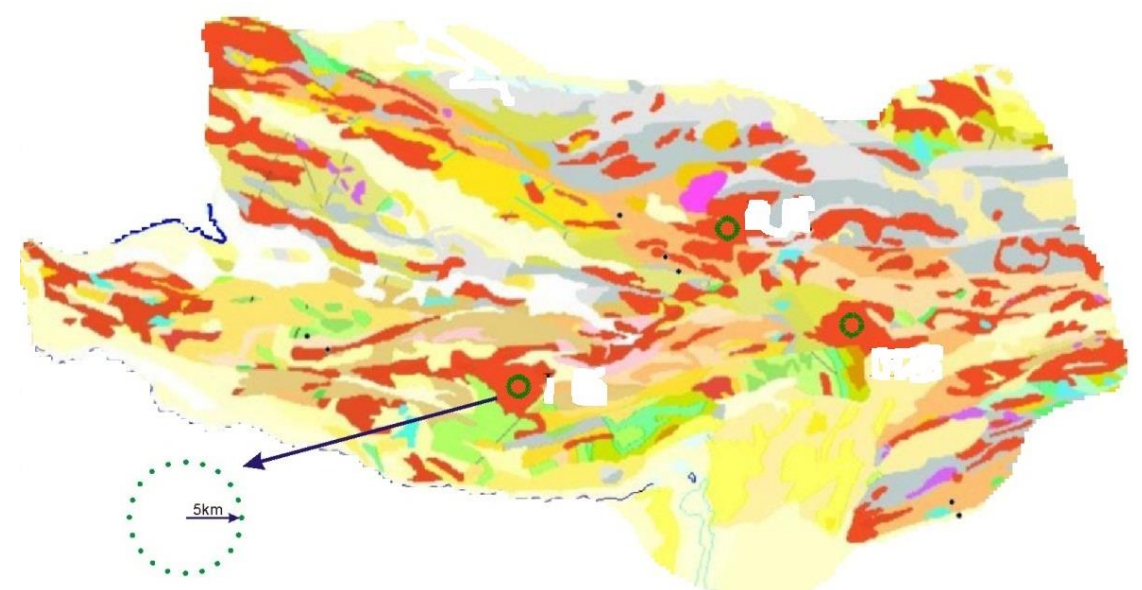

Figure 11. Tracer particle position map

\section{Basic scenario}

This scenario uses a combination of permeability coefficient and rainfall parameters as a basic scenario for the migration simulation of tracer particles. A simulation of 10,000 years was carried out, and the results of particle tracing are shown in Figure 12.

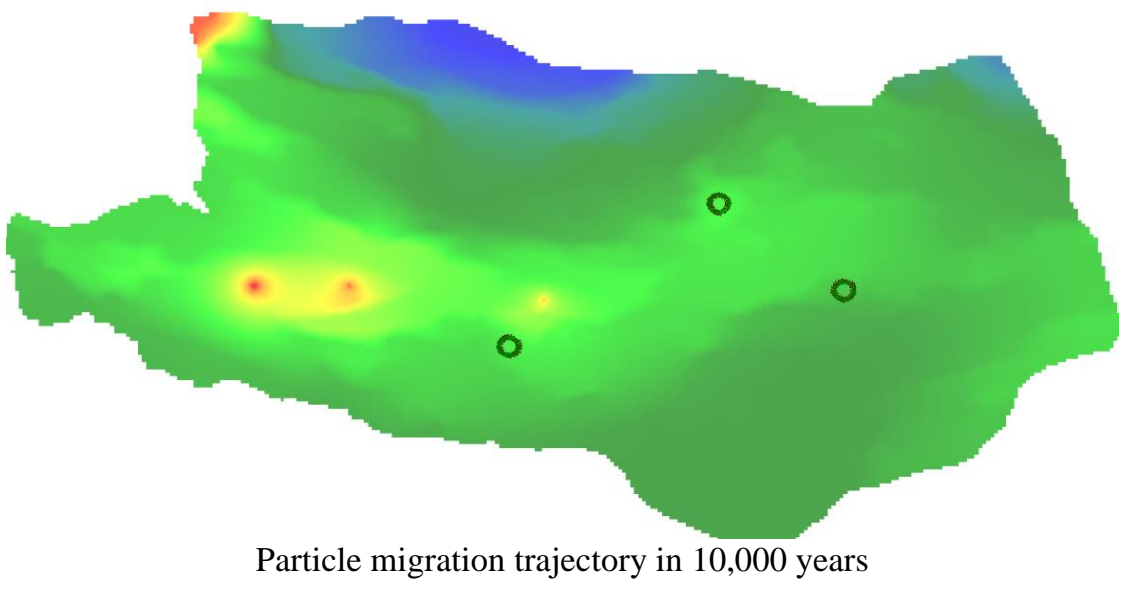

Figure 12. Basic scenario particle migration simulation results

\section{Scenario 1}

Scenario 1 considers the change trends of particle migration when doubling the permeability coefficient of granite. The partition values of the permeability coefficient used are shown in Table 7, and the simulation is carried out for 10,000 years. The results of particle tracing are shown in Figure 13.

Table 7. Scenario 1 permeability coefficient partition value

\begin{tabular}{c|c}
\hline Partition & Permeability coefficient value (m/d) \\
\hline K1 High permeability performance partition & 2.0 \\
K2 Medium permeability performance partition & 0.26 \\
K3 Low Permeability performance partition & 0.008 \\
\hline
\end{tabular}




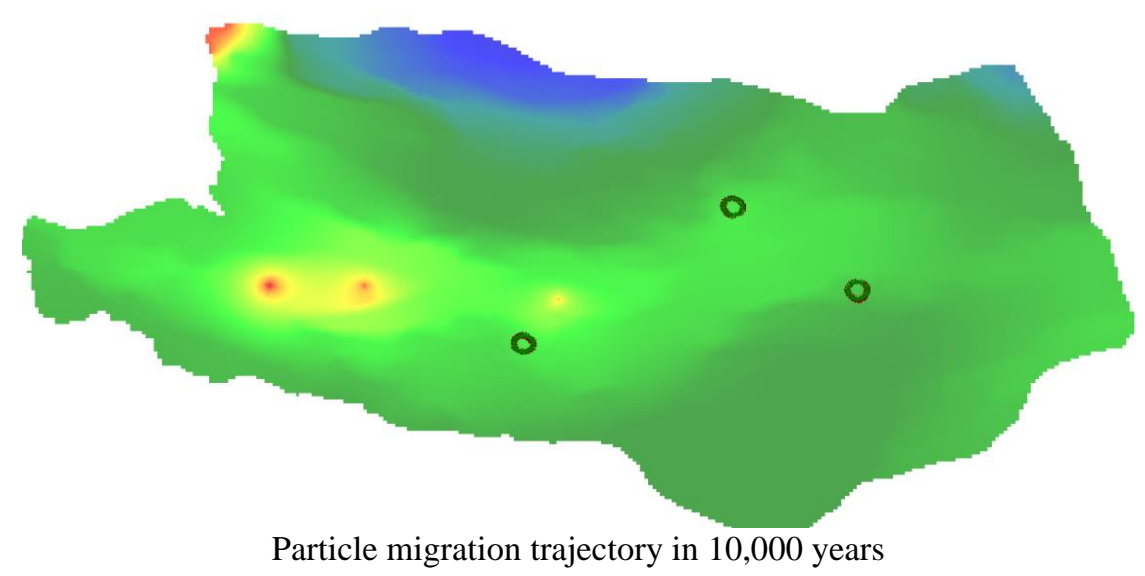

Figure 13. Scenario 1 particle migration simulation results

\section{Scenario 2}

Scenario 2 considers the variation trends of particle migration when the permeability coefficient of granite is reduced to half. The partition values of the permeability coefficient used are shown in Table 8, and the simulation is performed for 10,000 years. The results of particle tracing are shown in Figure 14.

Table 8. Scenario 2 permeability coefficient partition value

\begin{tabular}{c|c}
\hline Partition & Permeability coefficient value (m/d) \\
\hline K1 High permeability performance partition & 2.0 \\
K2 Medium permeability performance partition & 0.26 \\
K3 Low permeability performance partition & 0.002 \\
\hline
\end{tabular}

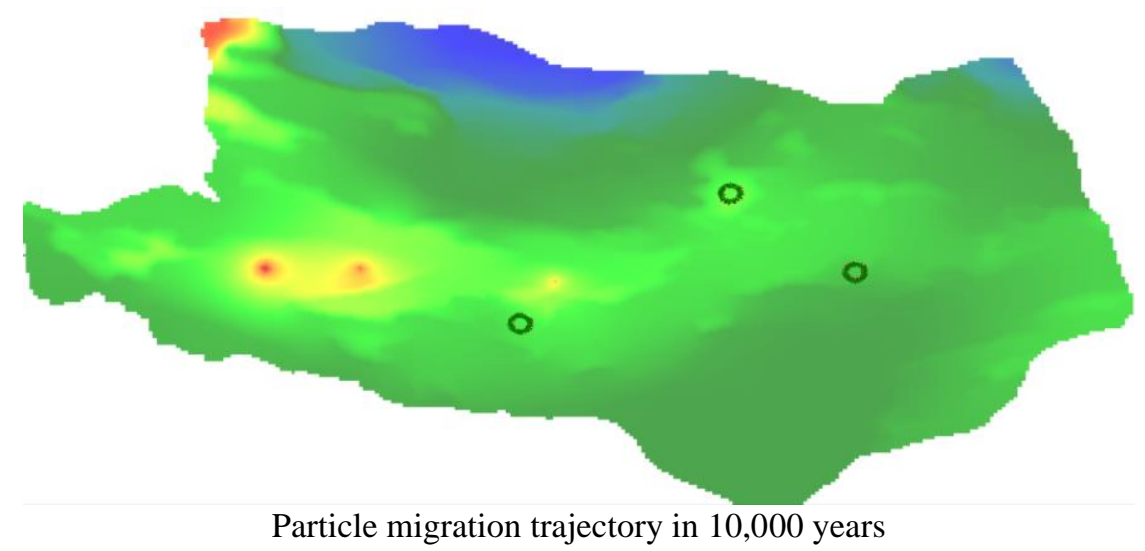

Figure 14. Scenario 2 particle migration simulation results

\section{Scenario 3}

Scenario 3 considers the trends of particle migration change when the precipitation is doubled, and simulates it for 10,000 years. The results of particle tracing are shown in Figure 15. 


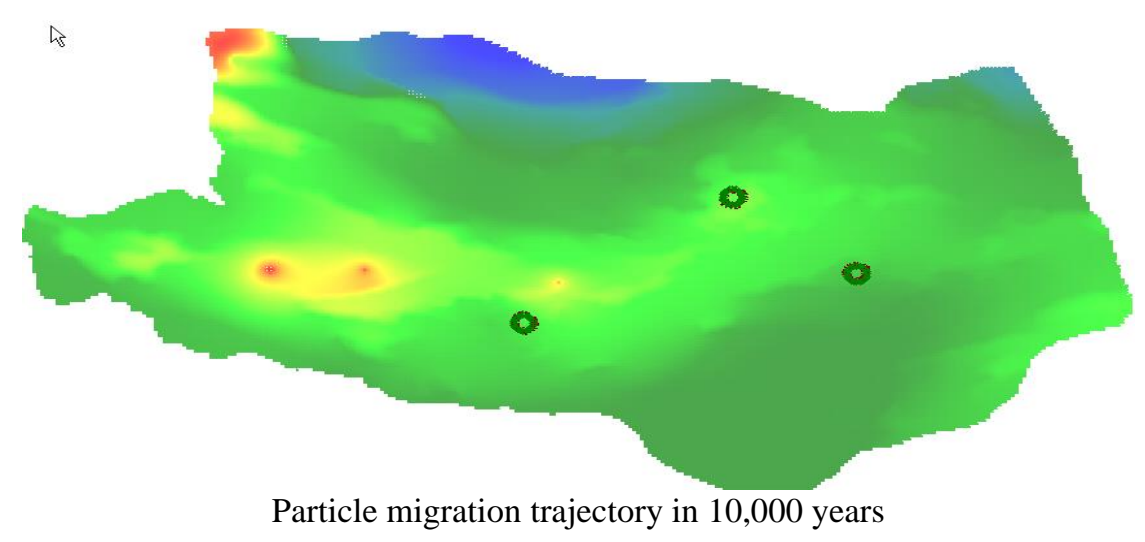

Figure 15. Scenario 3 particle migration simulation results

\section{Scenario 4}

Scenario 4 considers the trends of particle migration change when the precipitation is half reduced, and simulates for 10,000 years respectively. The results of particle tracing are shown in Figure 16.

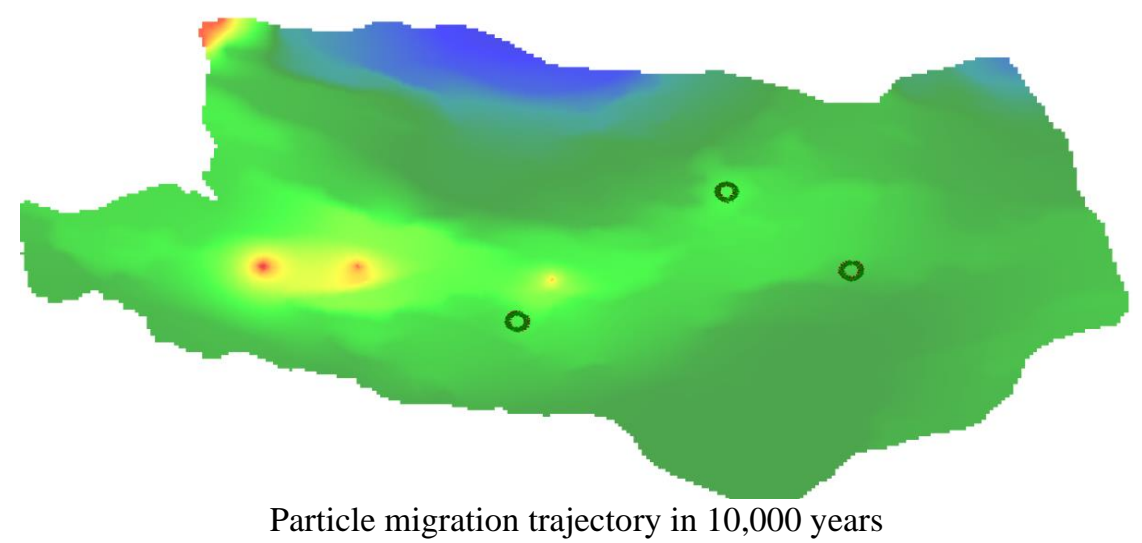

Figure 16. Scenario 4 particle migration simulation results

\section{Conclusion}

By analyzing the hydrogeological conditions of the Kuruktag region in Xinjiang, including the structure and boundary conditions of the aquifer system, the characteristics of the groundwater flow field, the hydraulic connection between different water-bearing units, and the relation between groundwater and surface water, the characteristics of the groundwater recharge and discharge, etc. are analyzed from the perspective of groundwater dynamics.

By adopting the combination of groundwater dynamics and field hydrogeological surveys and analyzing the hydrogeological conditions in the work area, the hydrogeological conditions are relatively simple, focusing on weakly water-bearing, low-permeability, slow flow rate, and relatively closed areas. Based on the above preparations, the simulation study of regional groundwater flow can be carried out, besides, the variation rules of regional groundwater flow under long-term scale is able to be predicted. 
Owing to the insufficient basic data and high uncertainty of large-scale model, the simulation of the groundwater flow of the model under multiple conditions and multiple scenarios by means of multi-scenario analysis. The study mainly considers the influence of permeability coefficient, precipitation change and fault on groundwater flow. Additionally, the particle tracing simulation is performed in three granite areas located in the eastern and central parts of the work area with six scenarios carried out by MODPATH to figure out the trajectories of nuclide migration in varied periods, reflecting the influencing factors and regularity of groundwater flow change and nuclide migration.

In order to comprehensively analyze and evaluate the particle migration conditions in multiple scenarios, the particle migration trajectories of the four scenarios are superimposed by 10,000 years of migration time respectively. The results of particle tracing are shown in Figure 17.

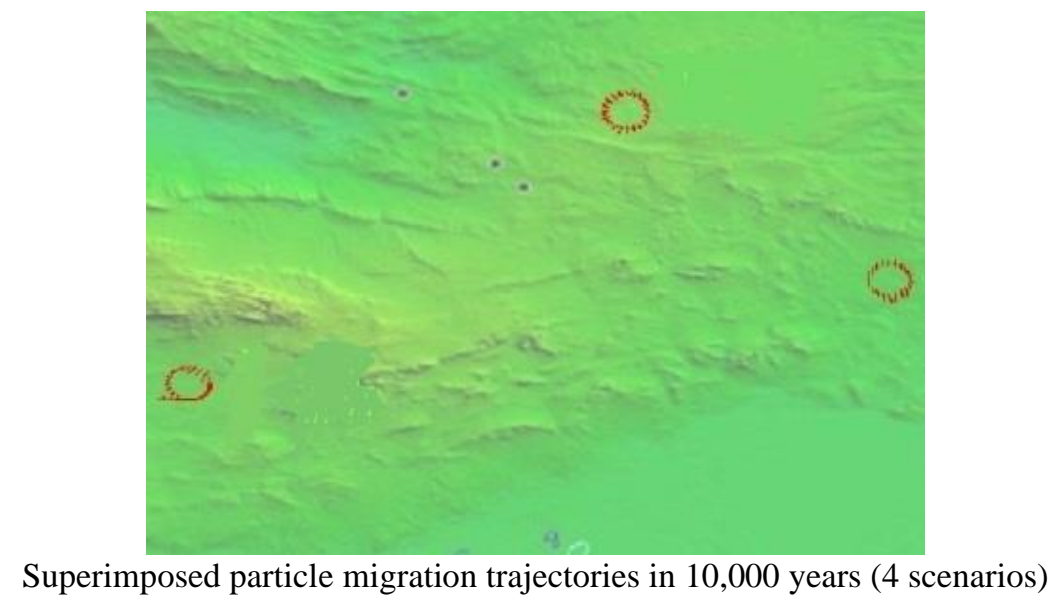

Figure 17. Comprehensive analysis of particle migration simulation in four scenarios

From the above superposition results, the trends of particle migration in each simulation period can be analyzed as follows: The migration of particles in the three regions is not large in 10,000 years, mainly moving along the direction of groundwater flow, and the migration length is 2 to $5 \mathrm{~km}$.

With the help of comprehensive analysis of particle motion in three regions under different scenarios in different periods, from the perspective of hydrogeology, the following conclusions can be drawn: the particle motion changes little under various scenarios, and the groundwater flow is stable subject to external conditions. The interference is small, the groundwater flow rate is relatively slow, and the particle migration speed is small.

Recommendations for future studies: (1) Due to scarce monitoring data of groundwater level, the interpolation of flow field would be distorted, which cannot represent the real flow field. To further correct the results of numerical simulation, the monitoring data of groundwater level should be enriched, and more hydrological drill holes are proposed to be set. (2) As the carrier of underground nuclide migration, groundwater should be defined as the circulation process. Numerical simulation of groundwater circulation is suggested to be conducted in the area with abundant monitoring data. Taking the petrological and hydrological conditions into consideration, the long-term groundwater circulation is able to be predicted. 


\section{REFERENCES}

[1] Blessent, D., Therrien, R., Gable, C. W. (2011): Large-scale numerical simulation of groundwater flow and solute transport in discretely-fractured crystalline bedrock. Advances in Water Resources 34(12): 1539-1552.

[2] Cao, G., Han, D., Currell, M. J., Zheng, C. (2016): Revised conceptualization of the North China Basin groundwater flow system: groundwater age, heat and flow simulations. - Journal of Asian Earth Sciences 127: 119-136.

[3] Chang, Z., Qi, W., Zhao, Z., Chen, X. (2001): Application of Isotope Techniques in Groundwater Exploration in Lop Nur Region. - Xinjiang Geology 19(3).

[4] Chen, M. (1993): Tectonic Style of the Turpan-Hami Basin. - Petroleum Exploration and Development 20(5): 1-7.

[5] Chen, Z. (1966): A brief history of the geological development of Kuruktag and the basic characteristics of geological structures. - Geological Review 24(3): 171-180.

[6] Second Hydrogeological Institute of Gansu Province (1995): Study on water transport and equilibrium factors of the aeration zone in the middle reaches of the Heihe River in Gansu Province. 1995: 23.

[7] Feng, X., Zhao, R., Li, J. (1994): Preliminary study on seismic geology in the Turpan Basin. - Inland Earthquake 8(2): 97-108.

[8] Jiang, Z., Xu, T., Owen, D. D. R., Jia, X., Feng, B., Zhang, Y. (2018): Geothermal fluid circulation in the Guide Basin of the northeastern Tibetan Plateau: isotopic analysis and numerical modeling. - Geothermics 71: 234-244.

[9] Jiao, P., Wang, Y., Liu, C. (2004): The strontium isotope characteristics and its geological significance of the salt lake brine in Lop Nur, Xinjiang. - Nuclear Technology 27(9): 710-715.

[10] Kendall, C. (1998): Tracing Nitrogen Sources and Cycling in Catchments. - In: Kendall, C., McDonnel, J. J. (eds.) Isotope Tracers in Catchment Hydrology. Elsevier, Amsterdam, pp. 534-569.

[11] Kihm, J.-H., Kim, J.-M., Song, S.-H., Lee, G.-S. (2007): Three-dimensional numerical simulation of fully coupled groundwater flow and land deformation due to groundwater pumping in an unsaturated fluvial aquifer system. - Journal of Hydrology 335(1): 1-14.

[12] Kolbe, T., Marçais, J., Thomas, Z., Abbott, B. W., de Dreuzy, J., Rousseau-Gueutin, P., Aquilina, L., Labasque, T., Pinay, G. (2016): Coupling 3D groundwater modeling with CFC-based age dating to classify local groundwater circulation in an unconfined crystalline aquifer. - Journal of Hydrology 543: 31-46.

[13] Lei, X., Liu, B., Quan, J., Wang, H. (2019): Review of the interactive relation between surface water and groundwater. - China Rural Water and Hydropower 19(5): 1-5.

[14] Liu, C., Wang, Y., Jiao, P. (1999): Hydrogen, oxygen, sulfur, isotope geochemistry and source of ore-forming minerals in Lop Nur salt lake, Xinjiang. - Deposit Geology 18(3): 268-275.

[15] Mengistu, H. A., Demlie, M. B., Abiye, T. A., Xu, Y., Kanyerere, T. (2019): Conceptual hydrogeological and numerical groundwater flow modelling around the Moab Khutsong deep gold mine, South Africa. - Groundwater for Sustainable Development 100266.

[16] Pétré, M.-A., Rivera, A., Lefebvre, R. (2019): Numerical modeling of a regional groundwater flow system to assess groundwater storage loss, capture and sustainable exploitation of the transboundary Milk River Aquifer (Canada - USA). - Journal of Hydrology 575: 656-670.

[17] Post, V. E. A., Galvis, S. C., Sinclair, P. J., Werner, A. D. (2019): Evaluation of management scenarios for potable water supply using script-based numerical groundwater models of a freshwater lens. - Journal of Hydrology 571: 843-855.

[18] SDIC Xinjiang Lop Nur Potash Co., Ltd. (2006): Detailed Report on the Potash Deposit of Luobei Depression in Ruoqiang County, Xinjiang. - SDIC Xinjiang Lop Nur Potash Co., Ltd., Bayingolin. 
[19] Shao, J., Li, Y., Hou, G., Wang, W., Zeng, L., Duan, L. (2017): Characteristics of groundwater circulation and evolution in Ili valley of Xinjiang. - Arid Zone Research 34(1): 20-25.

[20] Shi, K., Liu, B., Liu, H., Liu, J., Pan, W. (2017): Neoproterozoictectono-sedimentary evolution in Quruqtagh area, NE Tarim Basin, Xinjiang, China. - Earth Science Frontiers 24(01): 298-307.

[21] Singleton, M. J., Wood, K. N., Conrad, M. E., Depaolo, D. J., Dresel, P. E. (2005): Tracking sources of unsaturated zone and groundwater nitrate contamination using nitrogen and oxygen stable isotopes at the Hanford Site, Washington. - Environmental Science Technology 39: 3563-3570.

[22] Tatti, F., Papini, M. P., Torretta, V., Mancini, G., Boni, M. R., Viotti, P. (2019): Experimental and numerical evaluation of groundwater circulation wells as a remediation technology for persistent, low permeability contaminant source zones. - Journal of Contaminant Hydrology 222: 89-100.

[23] The Second Hydrogeology Engineering Geology Brigade of Xinjiang Geology and Minerals Bureau (2003): Hydrogeology and Geological Survey of Water Supply in Potash Mine of Lop Nur, Xinjiang. - Hydrogeology and Geological Survey Report of the Aqike Valley.

[24] Wang, J., Zhang, H., Zhang, G., Wu, F., Lei, K. (2018): Development and application of groundwater numerical simulation methods. - Environment and development 18(6): 103106.

[25] Wang, K. (2016): Analysis of groundwater formation and occurrence conditions in Korla Region, Xinjiang. -Groundwater 38(6): 253-254.

[26] Xia, X. (2007): China Lop Nur. - Science Press, Beijing.

[27] Xue, L., Wei, Q., Wei, G. (2018): Coupled simulation of surface water and groundwater in the main stream of Tarim River. - Journal of Hohai University (Natural Sciences) 47(3): 196-201.

[28] Zhou, X., Gao, Q., Chen, X., Yao, M., Zhao, X. (2013): Numerically simulating the thermal behaviors in groundwater wells of groundwater heat pump. - Energy 61: 240247.

[29] Zhu, W., Ma, R., Hu, D., Xu, M. (2001): Tectonic contact relationships between Qoltag Mountain and Turpan-Hami basin in Xinjiang. - Geotectonica et Metallogenia 25(2): 128-135. 